\title{
Pharmaciana
}

Vol.11, No.3, Nov 2021, Page. 406-415

ISSN: 2088 4559; e-ISSN: 24770256

DOI: 10.12928/pharmaciana.v11i3.19935

406

\section{Optimization transdermal patch of polymer combination of chitosan and HPMC-loaded ibuprofen using factorial designs}

\author{
Shaum Shiyan ${ }^{1,2}$, Misirti Maulidia Anis Marketama ${ }^{3}$, Galih Pratiwi $\mathbf{* 3 , 4}$ \\ ${ }^{1}$ Department of Pharmacy, Faculty of Mathematics and Natural Sciences, Universitas Sriwijaya, Indralaya (OI), \\ Jl. Raya Prabumulih Inderalaya Km 32, South Sumatera, Indonesia \\ ${ }^{2}$ Phytopharmaceutical Research Center (PRC), Department of Pharmacy, Faculty of Mathematics and Natural \\ Sciences, Universitas Sriwijaya, Indralaya (OI), South Sumatera, Indonesia \\ Jl. Raya Prabumulih Inderalaya Km 32, South Sumatera, Indonesia \\ ${ }^{3}$ Department of Pharmacy, STIKES 'Aisyiyah Palembang, \\ Jl. Kol. H. Burlian km 7.5, Palembang, South Sumatera, Indonesia \\ ${ }^{4}$ Biomaterials and Drug Delivery System (BiDDS) Research Group, STIKES 'Aisyiyah Palembang, \\ Jl. Kol. H. Burlian km 7.5, Palembang, South Sumatera, Indonesia
}

Submitted: 05-02-2021
Accepted: 09-10-2021

\begin{abstract}
Ibuprofen is a non-steroidal anti-inflammatory drug that has a disadvantage in its oral use, such as gastrointestinal disorders, nausea, vomiting and gastric ulcers. Transdermal patch dosage forms are an alternative in overcoming this weakness. The transdermal patch is formulated using a special membrane that can control drug release in a matrix system. Therefore, this study optimizes chitosan and HPMC as polymers using a factorial design approach. The parameters tested included weight uniformity, patch thickness, swelling index, in vitro release rate, folding resistance, ibuprofen uniformity, surface $\mathrm{pH}$, and moisture content. The interactions between the components were evaluated using Fourier transform infrared spectrophotometry-attenuated total reflectance (FTIRATR). The optimum concentration of chitosan was $0.5 \%$ and HPMC $6 \%$ with CV values for weight uniformity of $0.003 \pm 1.202 \%$; humidity $0.543 \pm 5.595 \%$; swelling index $4.611 \pm 23,657 \%$; thickness $0.052 \pm 2.428 \%$; surface $\mathrm{pH} 5$; durability is less than 300 times and the uniformity of ibuprofen levels is $1.52 \pm 2.99 \%$. The design approach using the FFD2 ${ }^{2}$ obtained an effective and efficient mathematical-statistical model to determine the optimal polymer combination in the formula. As an additional instrument in design evaluation, the chemometric approach is constructive in modeling and optimization.
\end{abstract}

Keywords: Ibuprofen, transdermal patch, full factorial design, chitosan, HPMC

\footnotetext{
*Corresponding author:

Galih Pratiwi

Department of Pharmacy, STIKES Aisyiyah Palembang,

J1. Kol. H. Burlian km 7.5, Palembang, South Sumatera, Indonesia

Email: galihpratiwi@stikes-aisyiyah-palembang.ac.id
} 


\section{INTRODUCTION}

Ibuprofen has been widely used in therapy as an analgesic (Motov et al., 2020), antiinflammatory, antipyretic and reduces rheumatoid arthritis symptoms (Wang et al., 2020). This active substance can reduce the number of prostaglandins, inhibit cyclooxygenase-1 (COX-1), and inhibit cyclooxygenase-2 (COX-2) (Romero-Chávez et al., 2018). Tracing reports and publications to date, oral use causes side effects of gastric ulcers, gastrointestinal disorders, nausea, vomiting, headaches, and bleeding (Kumar et al., 2013). Based on the biopharmaceutical classification system (BCS), ibuprofen is classified in Class II (Darusman et al., 2021). Therefore, to overcome side effects, increase solubility, and improve its release, it can be formulated in the form of a transdermal.

Most of the inflammatory diseases occur locally and close to the body's surface so that transdermal preparations are expected to have a direct pharmacological effect and have a fast action. One of the transdermal dosage forms that can be effectively used for drug delivery is a patch (Kumar et al., 2013). Transdermal patches come in a plaster-like dosage form that is applied to the skin. The patch matrix can deliver specific drug doses through the skin (transdermal) into the bloodstream. The patch matrix is formulated using a special membrane that can control drug release in the system. This delivery system can avoid first-pass drug metabolism, easy to stop use in case of toxic effects, provides a constant drug concentration, reduces drug side effects indigestion, and maintains the bioavailability of drugs in plasma. Patches are also more able to guarantee dosage accuracy than gel or ointment preparations (Santos et al., 2018).

The patch matrix has a patch type with minimal membrane leakage so that large amounts of drug release do not occur (Tyagi and Goyal, 2017). A critical component of the patch matrix for regulating the release rate is a polymer. Chitosan and HPMC were chosen because the hydrophobic and hydrophilic properties of each polymer strongly support drug release. Combining the two polymers aims to obtain a more effective drug release. Chitosan is hydrophobic, has antimicrobial activity, and is quickly processed in various products. Chitosan also has good stability and low toxicity (Pratiwi et al., 2019). HPMC is hydrophilic, easily hydrated by water, so it expands easily and accelerates drug release. The use of HPMC polymers without a rate regulating membrane will release the drug rapidly. Therefore, it is very interesting to combine it with chitosan.

The optimum composition of the chitosan-HPMC combination in the patch matrix formulation can be designed using a factorial approach. Designs were evaluated using chemometric analysis to determine the pattern of proximity and correlation of defined responses (Shiyan et al., 2020). The combination of this multivariate analysis provides more information in the optimization procedure. Finally, the design of experiment (DoE) and multivariate analysis using chemometrics can obtain the optimal formula for the ibuprofen patch with chitosan and HPMC constituent polymers in the transdermal drug delivery system (TDDS) effectively and efficiently.

\section{MATERIALS AND METHOD Materials}

Ibuprofen was obtained from PT. Phapros (Semarang, Indonesia) and chitosan were purchased from PT Multiguna (Indonesia). Materials such as HPMC, propylene glycol, polyethyleneglycol 400 were purchased from Bratachem (Jakarta, Indonesia).

\section{Optimization using Full Factorial Design (FFD)}

The combination of chitosan and HPMC polymers in the patch formulation was designed using a FD2 ${ }^{2}$ approach. The number of trial runs is determined using the Design-Expert software. The independent factor used is chitosan (A) with a level of $0.5-1 \%$ and HPMC (B) with $2-6 \%$. The responses used for optimization evaluation on FFD $2^{2}$ consist of weight uniformity $\left(\mathrm{R}_{1}\right)$, moisture content $\left(\mathrm{R}_{2}\right)$, swelling index $\left(\mathrm{R}_{3}\right)$, and thickness $\left(\mathrm{R}_{4}\right)$. The complete experimental design and results are shown in Table 1. 
Table 1. Full Factorial design $2^{2}$ and complete formula of ibuprofen patch-transdermal

\begin{tabular}{cccccc}
\hline \multirow{2}{*}{ Ingradient } & Function & \multicolumn{4}{c}{ Formula } \\
\cline { 3 - 6 } & & Run 1 & Run 2 & Run 3 & Run 4 \\
\hline A: Chitosan (\%) & Polymer & 0.50 & 0.50 & 1.00 & 1.00 \\
B: HPMC (\%) & Polymer & 6.00 & 2.00 & 2.00 & 6.00 \\
Ibuprofen (mg) & Active substance & 25.00 & 25.00 & 25.00 & 25.00 \\
PG (\%) & Enhancer & 10.00 & 10.00 & 10.00 & 10.00 \\
PEG 400 (\%) & Plasticizer & 20.00 & 20.00 & 20.00 & 20.00 \\
\hline Responses (\%CV) & & & & \\
R $_{1}$ : Weight uniformity & 2.28 & 2.08 & 2.09 & 2.30 \\
R $_{2}$ : Moisture content & 9.03 & 12.66 & 11.96 & 20.54 \\
R $_{3}$ : Swelling index & 23.75 & 26.28 & 27.02 & 24.15 \\
R4: Thickness & 4.20 & 4.79 & 5.98 & 2.98 \\
\hline
\end{tabular}

\section{Patch preparation}

Chitosan stock solution was prepared by dissolving $1 \mathrm{~g}$ in $100 \mathrm{~mL}$ of $1 \%$ acetic acid. A total of $10 \mathrm{~g}$ of HPMC powder was dissolved with $100 \mathrm{~mL}$ of distilled water. Each was diluted as needed in the experimental design. Chitosan solution with a concentration according to Table 1 was poured into a beaker and stirred continuously during the magnetic film making process. Furthermore, $25 \mathrm{mg}$ of ibuprofen was added to the mixture. PEG 400 as a plasticizer and propylene glycol as an enhancer was added. The mixture was poured into a petri dish with a diameter of $5.5 \mathrm{~cm}$ (after the bubbles were removed) and put in an oven at $60{ }^{\circ} \mathrm{C}$ for 40 hours. Then the film preparations were stored in an airtight container and filled with silica for 4 days (constant weight was achieved). Visually dry patches with a surface that does not appear to be moist and evenly dry are removed from the cup.

\section{Determination of weight uniformity}

The weight uniformity test was carried out following Patel et al. (2012) with slight modifications. A total of ten matrices that have been cut with a size of $1 \times 1 \mathrm{~cm}$ each were weighed. Test evaluation is based on the calculation of the coefficient variation $(\mathrm{CV} ; \%)$ of the number of matrices weighed.

\section{Determination of moisture content}

The moisture content test was conducted to determine the amount of water content in the patch preparation, which could affect the stability of the preparation. Each patch measuring $1 \mathrm{x} 1 \mathrm{~cm}$ that has been prepared is weighed and stored in a desiccator containing silica gel at $30{ }^{\circ} \mathrm{C}$ for 24 hours. The patches are then weighed again (final weight).

\section{Determination of swelling index}

The patch matrix with a size of $1 \mathrm{x} 1 \mathrm{~cm}$ was put into a petri dish containing a phosphate buffer at a $\mathrm{pH}$ of 6.8. At specific minutes $(5,15,30$ and 60$)$ the patch matrix was taken, and the remaining liquid on the surface was absorbed with filter paper before weighing (Singh and Prajapati, 2017).

\section{Determination of patch thickness}

The thickness of the patch matrix is targeted to be no more than $1.0 \mathrm{~mm}$ - thickness test by measuring a patch matrix at four different points. The mean, standard deviation and coefficient variation were calculated to determine the thickness for each patch (Patel et al., 2012). 


\section{Determination of folding endurance}

The folding endurance is carried out by folding the matrix at the same point repeatedly until it breaks (Patel et al., 2012). The patch matrix in this test has a size of $1 \times 1 \mathrm{~cm}$. The patch matrix is classified as useful with a folding endurance value of more than 300 times.

\section{In vitro drug release assay}

The in vitro release of ibuprofen was carried out using a modified vertical type Franz diffusion cell. The donor section contains a patch matrix with a size of $1 \mathrm{x} 1 \mathrm{~cm}$ and ibuprofen $25 \mathrm{mg}$. Separation of the donor and acceptor compartments using a cellophane membrane. A cut of the membrane according to the size of the diffusion cell is placed between the donor and acceptor compartments with the dermis side facing the acceptor compartment. The acceptor compartment contains $15 \mathrm{~mL}$ of phosphate buffer $\mathrm{pH} 7.4$ and stirred with a magnetic stirrer at $600 \mathrm{rpm}$ at $37 \pm 0.5$ ${ }^{\circ} \mathrm{C}$ (Ramkanth et al., 2015). Observations were made for 3 hours, and samples were taken at 5, 10, 20, $30,60,90,120,180$ minutes for each time taking $1 \mathrm{~mL}$ of samples. Each sampling was replaced with $1 \mathrm{~mL}$ of the same phosphate buffer solution in the assay. The absorption is measured at the maximum absorption wavelength and can be determined the amount of drug that is penetrated.

\section{Spectra FTIR-ATR}

Spectra patterns from Fourier transform infrared (FTIR-ATR) instrumentation can be used to study the physical and chemical interactions between drugs and additives (Pratiwi et al., 2019). The interaction between ibuprofen and the polymer was evaluated qualitatively by observing changes in peaks and shifts in specific wavenumbers. The readings of IR spectra were carried out on the pure components of ibuprofen, chitosan, HPMC, propylene glycol, PEG-400 and the formulated patch matrix. Each of the samples was placed in a holder and measured at a wavenumber of $4000-500 \mathrm{~cm}^{-1}$ (Pratiwi et al., 2020; Sabati et al., 2017; Shiyan et al., 2018).

\section{Data Analysis}

The four runs of the experimental results according to the design were expressed as mean \pm standard deviation $(n=3)$. The data were analyzed and then obtained a contour plot of each response to the factor. The contour plot is combined into a contour plot superimposed/ overlay plot to determine the optimum composition of the combination of chitosan and HPMC to be used as the polymer. The approach uses principal component analysis (PCA) and cluster analysis (CA) to evaluate the degree of formula similarity and response correlation (Kartini et al., 2021; Shiyan et al., 2020).

\section{RESULT AND DISCUSSION}

\section{Optimization using full factorial design $\mathbf{2}^{2}$}

The patch matrix is designed to regulate drug release, increase penetration so that it can be delivered to the circulatory system (Patel et al., 2012). The patch consists of two layers, and the first contains ibuprofen, a polymer, and other additives (namely matrices). The second layer is the backing as a diffusion barrier for ibuprofen and the direction of diffusion of the active substance (Singh and Prajapati, 2017).

Figure 1 presents the results of the patch matrix of 4 runs or formulas. The matrix at run 1 (chitosan $0.5 \%$ and HPMC 6\%) produced good physical characteristics (Table 1; Figure 1A). The formulations in run 2 (chitosan $0.5 \%$ and HPMC 2\%) have softer properties due to the lower construction of each polymer (Figure 1B). Run 3 at Figure 1C formulation produces a patch matrix that is slightly stiff due to the high concentration of chitosan. The formulation on the run four also produces stiff and rigid patches and uneven surfaces because each high concentration can increase the thickness of the solution before the printing process (Figure 1D). The results of research by Sarath et al. (2013) revealed that $0.5 \%$ chitosan provided the optimum patch. Therefore, the FD is used at a low level. Overall, from the statistical evaluation of the four models $\left(R_{1}, R_{2}, R_{3}\right.$ and $\left.R_{4}\right)$, good modelling results are obtained to be used in determining the optimal prediction of polymer blends. Modelling 
details related to the type of model, transformation status, and regression equation are presented in Table 3. Only in response 2 (moisture content) was transformed because the experimental data had not met the initial requirements so that the transformation had to be carried out.
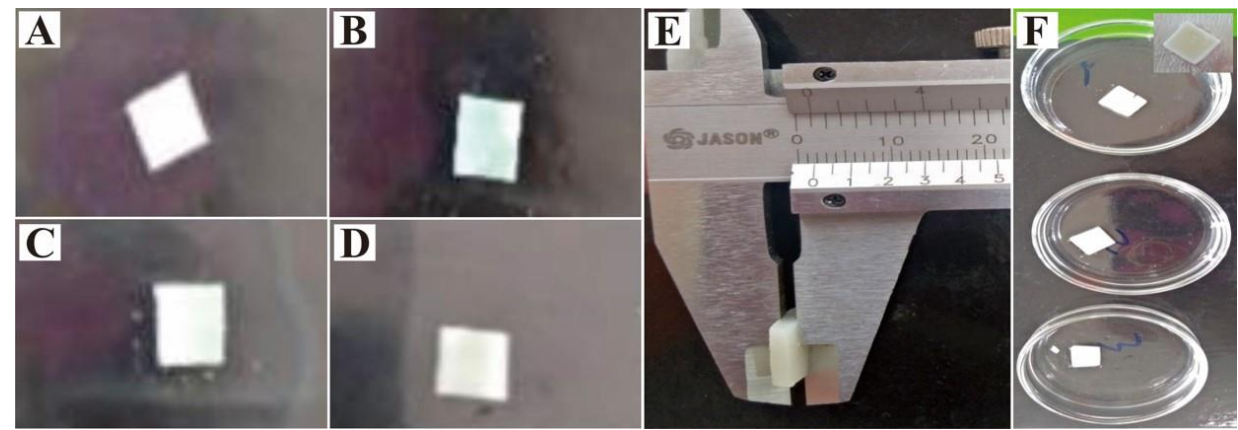

Figure 1. Transdermal patch matrix from FD design, (A) run 1, (B) run 2, (C) run 3, (D) run 4, (E) thickness measurement, (F) swelling index measurement with 3 replicate from optimum formulas

Tabel 2. Complete analysis of the evaluated responses in the FFD design optimization of polymer patch matrix components

\begin{tabular}{ccccccccc}
\hline Responses & \multicolumn{8}{c}{ Parameters } \\
\cline { 2 - 9 } & Mean & $\begin{array}{l}\text { Standard } \\
\text { deviation }\end{array}$ & $\begin{array}{l}\text { CV } \\
(\boldsymbol{\%})\end{array}$ & Press & $\boldsymbol{R}^{\mathbf{2}}$ & $\begin{array}{c}\text { Adjusted } \\
\boldsymbol{R}^{\mathbf{2}}\end{array}$ & $\begin{array}{c}\text { Predicted. } \\
\boldsymbol{R}^{\mathbf{2}}\end{array}$ & $\begin{array}{c}\text { Adequate } \\
\text { precision }\end{array}$ \\
\hline $\mathrm{R}_{1}$ & 2.19 & 0.01 & 0.51 & 0.001 & 0.9941 & 0.9911 & 0.9763 & 25.93 \\
$\mathrm{R}_{2}$ & 0.08 & 0.001 & 1.97 & 0.00 & 0.9987 & 0.9961 & 0.9792 & 45.16 \\
$\mathrm{R}_{3}$ & 25.30 & 0.42 & 1.66 & 1.42 & 0.9537 & 0.9306 & 0.8149 & 9.08 \\
$\mathrm{R}_{4}$ & 4.49 & 0.02 & 0.33 & 0.004 & 1.0000 & 0.9999 & 0.9992 & 230.94 \\
\hline
\end{tabular}

Note: $\mathrm{R}_{1}=$ weight uniformity; $\mathrm{R}_{2}=$ moisture content; $\mathrm{R}_{3}=$ swelling index; $\mathrm{R}_{4}=$ thickness

Table 3. Transformation status, model type and regression equation for each response

\begin{tabular}{cccc}
\hline Responses & Transformation & Model & Regression equation \\
\hline $\mathrm{R}_{1}$ & No & Main effects & $\mathrm{R}_{1}=2.19+0.10 \mathrm{~B} \ldots \ldots \ldots \ldots \ldots . \ldots(1)$ \\
$\mathrm{R}_{2}$ & Inverse & Reduced $2 \mathrm{FI}$ & $\mathrm{R}_{2}=0.08-0.01 \mathrm{~A}-0.02 \mathrm{AB} \ldots \ldots .(2)$ \\
$\mathrm{R}_{3}$ & No & Reduced main effects & $\mathrm{R}_{3}=25.30-1.35 \mathrm{~B} \ldots \ldots \ldots \ldots \ldots(3)$ \\
$\mathrm{R}_{4}$ & No & Reduced $2 \mathrm{FI}$ & $\mathrm{R}_{4}=4.49-0.90 \mathrm{~B}-0.60 \mathrm{AB} \ldots \ldots .(4)$ \\
\hline
\end{tabular}

Note: $\mathrm{R}_{1}=$ weight uniformity; $\mathrm{R}_{2}=$ moisture content; $\mathrm{R}_{3}=$ swelling index; $\mathrm{R}_{4}=$ thickness

\section{Fitting model of weight uniformity response $\left(\mathbf{R}_{1}\right)$}

The predicted vs actual value of the weight uniformity is not too different with the difference between adjusted $R_{2}$ and predicted $R_{2}$ being less than 0.2 . The model for $R 1$ indicates that there is no significant difference between the observed data and the predicted data. Based on regression equation 1 (Table 3), HPMC is more dominant in influencing the weight uniformity of the patch matrix. Chitosan is a polymer that can interact and absorb active compounds from the patch in a certain amount so that the HPMC-chitosan (AB) interaction will increase weight uniformity (Kulig et al., 2017). The effect of the polymer on the weight uniformity parameters is highlighted on the contour plot and 3D surface plot (Figure 2A). The blue area indicates that the result is less than the red area. High HPMC concentrations and low chitosan concentrations can reduce the $\% \mathrm{CV}$ response to weight uniformity (blue area). A low \%CV value indicates excellent matrix weight uniformity. Systematically and scientifically, the FFD approach will provide a better interpretation. In theory, HPMC with high concentration and low level of chitosan obtained a low \%CV weight uniformity. 
Fitting model of moisture content response $\left(\mathbf{R}_{2}\right)$

Based on equation 2 (Table 3), chitosan (A) and the interaction of chitosan-HPMC (AB) effect decreasing the $\mathrm{CV}$ value of moisture content. The interaction scheme in (Figure 2F) shows the concentrations of HPMC and chitosan with different constructions resulting in different moisture responses. The polymer effect on moisture was confirmed on the contour plot and 3D surface (Figure 2B). The blue area indicates that the CV is worth less than the red area. High levels of HPMC and low levels of chitosan can reduce the response indicated by the blue area.
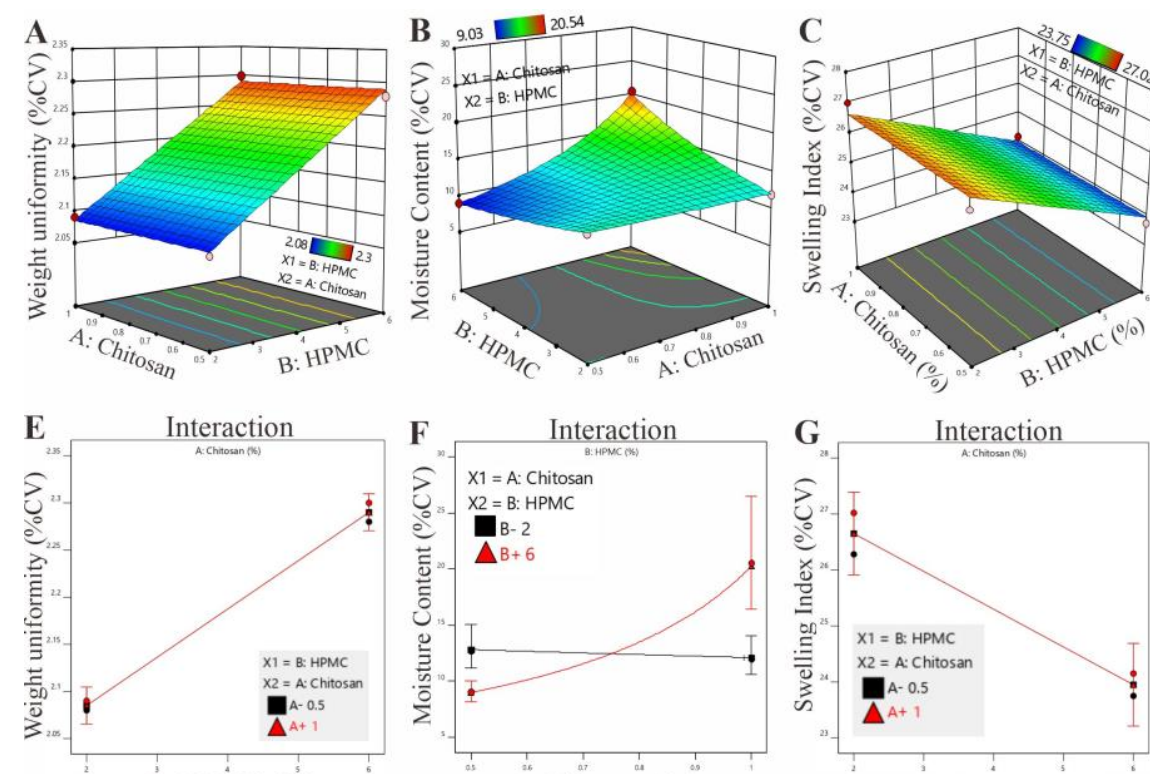

B: $\operatorname{HPMC}(\%)$
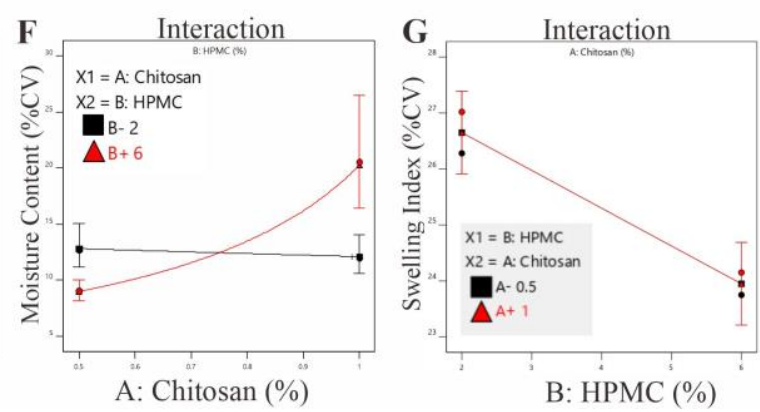
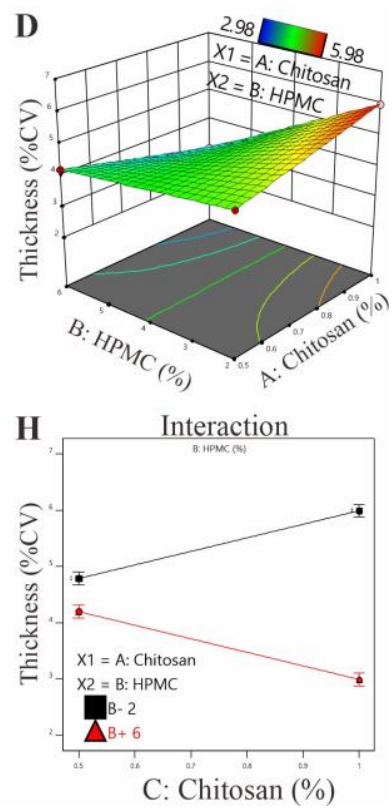

Figure 2. Results of model analysis, (A) 3D surface plot of weight uniformity, (B) 3D surface plot of moisture content, (C) 3D surface plot of swelling index, (D) 3D surface plot of thickness, (E) interaction from weight uniformity response, (F) interaction from moisture content response, (G) interaction from swelling index response, (H) interaction from thickness response

\section{Fitting model of swelling index response $\left(\mathbf{R}_{3}\right)$}

Chitosan can form hydrogen bonds intramolecularly and between molecules in its structure. An increase in the swelling index occurred at the 5th minute. Hydrophilic and hydrophobic polymers absorb water very quickly due to the empty cavity containing the solvent which diffuses into the patch and accelerates the dissolution of the gel. HPMC affects the increase in the swelling index (Table 3, Equation 3). The effect of the polymer on the swelling index is highlighted in contour plots and 3D surface plots (Figures 2C).

\section{Fitting model of thickness response $\left(\mathbf{R}_{\mathbf{4}}\right)$}

The thickness of the matrix affects the physical properties and the folding resistance. Patch thickness is uniform with good test reproducibility. Model fittings show that the data are normally distributed and meet the requirements of statistical analysis. Based on equation 4 (Table 3), HPMC greatly affects the thickness of the matrix.

\section{Chemometrics analysis approach}

The chemometric approach is used to evaluate the design used in optimization. The results of the analysis indicate that the four formulas do not group. Each of them has different characters, which indicates that the early stages of modeling are going well. The FD design cannot easily explain the 
correlation between responses, but the PCA results can be seen quickly by loading the plot. The complete results of the analysis using the PCA-CA technique are shown in Figure 3.
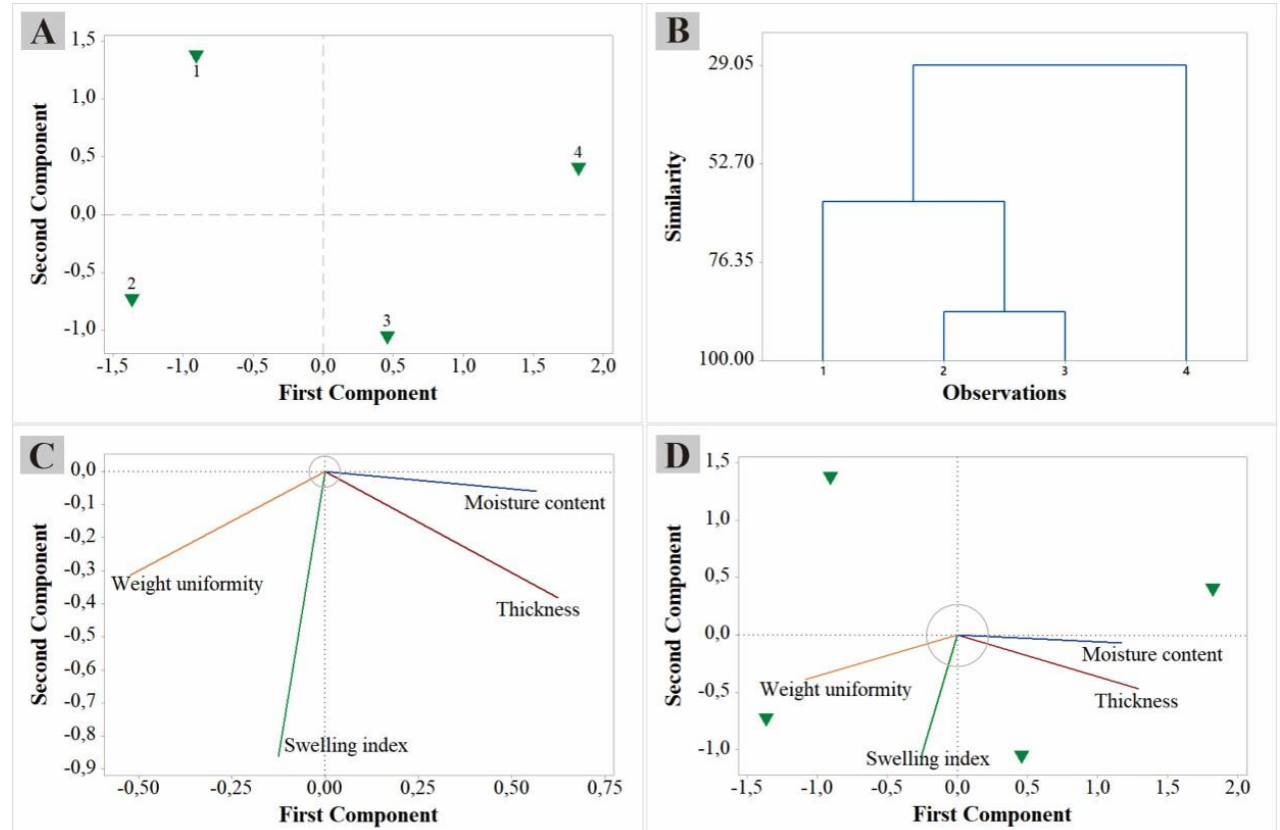

Figure 3. (A) Score plot, (B) Dendrogram, (C) Loading plot, (D) Biplot

\section{Prediction of the optimal formula and verification of results}

The desire score expresses how close the predicted response value is to the desired response value. The desirability values close to 1 indicate closeness to the predicted value. Verification of the optimal formula is done by looking at the predictive value consisting of a confidence interval $(95 \% \mathrm{CI})$ and a prediction interval (95\% PI). The confidence interval is the value range of the average observed results at the $95 \%$ confidence level, and the prediction interval is the range of the predicted individual values observed at the 95\% confidence level (Shiyan et al., 2019; Weissman and Anderson, 2015).

Tabel 4. The optimum predictive value and verification range

\begin{tabular}{ccccccc}
\hline Respon & Prediksi & Observasi & $\begin{array}{c}\text { 95\% Cl } \\
\text { low }\end{array}$ & $\begin{array}{c}\text { 95\% CI } \\
\text { high }\end{array}$ & $\begin{array}{c}\text { 95\% TI } \\
\text { low }\end{array}$ & $\begin{array}{c}\text { 95\% PI } \\
\text { high }\end{array}$ \\
\hline $\mathrm{R}_{1}$ : Weight uniformity & 2.29 & 1.20 & 2.19 & 2.39 & 1.82 & 2.76 \\
$\mathrm{R}_{2}$ : Moisture content & 10.00 & 5.60 & 8.81 & 11.56 & 5.82 & 35.56 \\
$\mathrm{R}_{3}$ : Swelling index & 23.95 & 23.66 & 22.67 & 25.24 & 18.29 & 29.62 \\
$\mathrm{R}_{4}$ : Thickness & 3.97 & 2.25 & 3.84 & 4.11 & 3.35 & 4.59 \\
\hline
\end{tabular}

\section{Optimum formula characterization}

Based on the optimal formula testing, it was obtained that the average $\mathrm{CV}$ of patch weight was $0.25 \pm 0.003 \%$ which fulfilled the requirements of less than $5 \%$ (Patel et al., 2012). Moisture content $9.71 \pm 0.54$ according to the requirements not more than $10 \%$. The bigger the HPMC and chitosan construction formed in the matrix, the greater the moisture content. The swelling index with an average of $19.50 \pm 4.61 \%$, this indicates that the swelling ability is too small, the release of ibuprofen is getting smaller. The optimal matrix thickness is $2.15 \pm 0.05 \mathrm{~mm}$. 
The $\mathrm{pH}$ value ensures that the matrix is harmless and does not irritate the skin. The normal $\mathrm{pH}$ value on the patch is 5-7, while the measurement on the matrix obtained $\mathrm{pH} 5$. The folding resistance test aims to determine the folding capacity of the matrix. A patch is said to be good if it has a resistance value of more than 300 times. Patches that do not have good resistance will make easily brittle and tear. The plasticizer binds to the polymer matrix which can increase the volume of blanks between the polymer chains. Therefore, it allows the chain segments to move freely, thereby increasing polymer movement, making the matrix more flexible and elastic.

The uniformity of ibuprofen was $50.81 \pm 1.52 \%$, where the results obtained did not meet the requirements. This can be caused by the instability of the ibuprofen compound in its manufacture, the presence of impurities, the influence of temperature, oxygen, and light. Exposure to oxygen and light during the manufacturing process can lead to decreased levels of the compound ibuprofen. Extraction of compounds from the matrix is not optimal or even takes longer for the compound to be completely extracted from the polymer matrix. The diffusion test graph shows that at the 5th minute the penetration starts to increase, and the 30th minute reaches the highest position. At 60, 120, and 180 minutes showed ibuprofen release (Figure 4A).

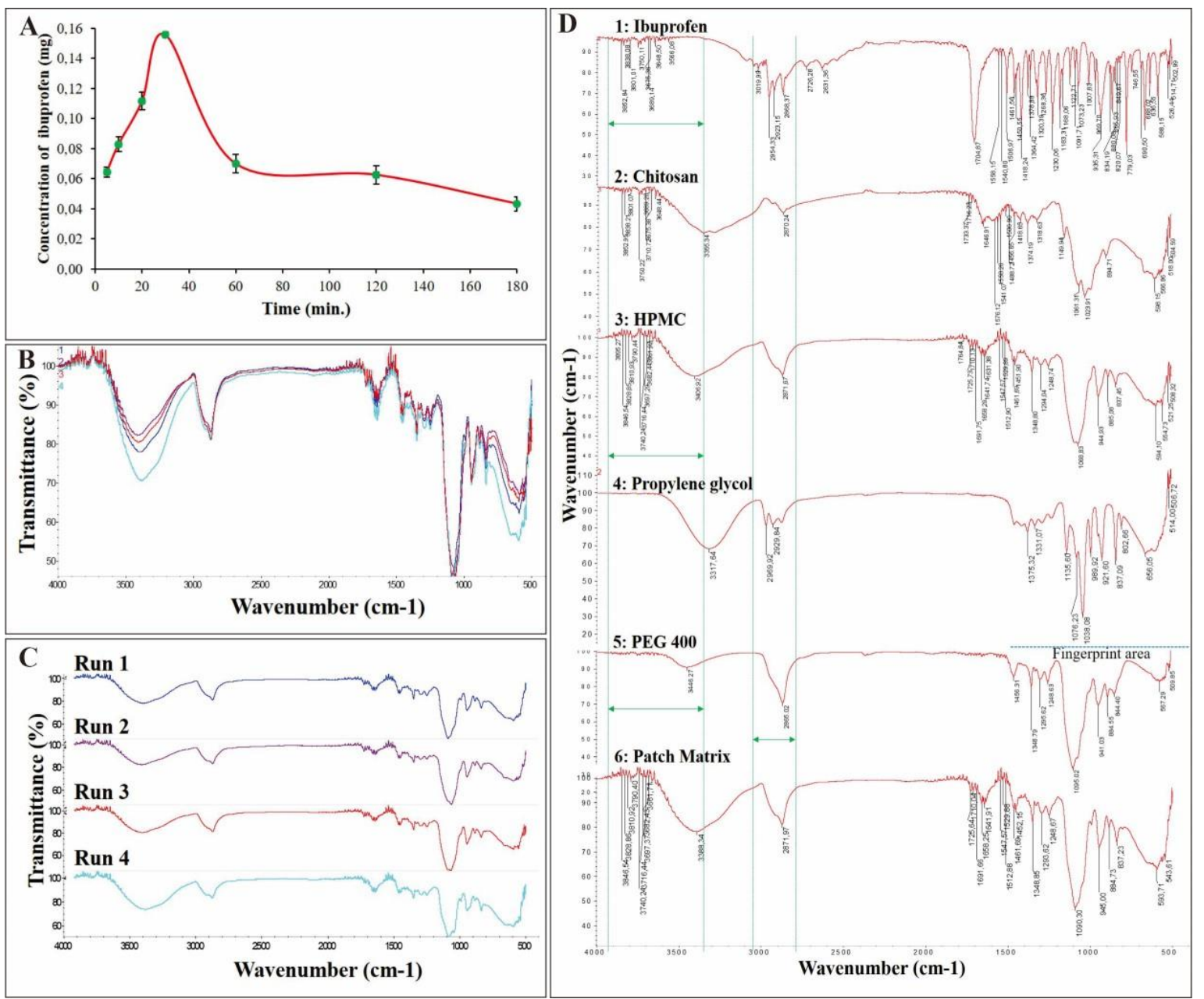

Figure 4. (A) In vitro release of ibuprofen of optimum formula, (B) Overlay spectra of 4 run in factorial design, (C) FTIR-ATR spectra pattern for each run, (D) FTIR-ATR spectra of each component of the matrix 


\section{Interaction study using Fourier Transform Infrared (FTIR)}

Figure 4 shows the IR spectra pattern of the identified sample. The overlay of the four runs (Figure 4B) shows no difference in spectral patterns. Figure 4C is the separation between the overlay and steaking between run 1 to run 4 . The $\mathrm{O}-\mathrm{H}$ strain in a wider spectrum of patches characterizes the hydroxyl group of the compound ibuprofen. The area of 1500-500 $\mathrm{cm}^{-1}$ in the ibuprofen patch spectra is a fingerprint that is still visible in the patch spectra. The transmittance intensity is determined by the concentration of the sample used. The intensity is also influenced by the polarity of the functional group, the stronger the functional group, the stronger the absorption and the greater the vibration.

The presence of $\mathrm{OH}$ in the wide patch matrix causes the $\mathrm{NH}_{2}$ of the chitosan to be covered. The $\mathrm{OH}$ group between pure chitosan and the patch matrix is also known to experience a shift in wavenumber (Pratiwi et al., 2019). The addition of PEG 400 and PG plasticizers as enhancers in the formula greatly affects the occurrence of the $\mathrm{OH}$ shift phenomenon in the spectral pattern. Based on this, the matrix system describes the formation of new bonds between chitosan and other constituent components. This phenomenon makes the $\mathrm{OH}$ bond in the chitosan polymer chain in the patch matrix weak. The results of the FTIR-ATR analysis indicate that the physical mixing process in the patch matrix formulation was successful, which was characterized by the presence of hydrogen interactions between chains.

\section{CONCLUSION}

The patch produced from chitosan and HPMC has good characteristics, elastic texture, and high swelling index so that it will provide a good pharmacological effect. The optimum concentrations of chitosan and HPMC needed to produce the optimum formula were chitosan concentrations of $0.5 \%$ and HPMC of $6 \%$. The release profile of ibuprofen resulted in an appropriate and controlled release at 60 minutes. The chemometric analysis was successful in providing information in completing the evaluation of the design of FFD2 ${ }^{2}$.

\section{ACKNOWLEDGEMENT}

The author is grateful to the Biomaterials and Drug Delivery System (BiDDS) Research Group, Departement of Pharmacy STIKES 'Aisyiyah Palembang. Thanks to Department of Pharmacy, Faculty of Mathematics and Natural Sciences, and LPPM Universitas Sriwijaya.

\section{REFERENCES}

Darusman, F., Ayustine, D. P., Noerman, S., Priani, S. E., \& Shalannandia, W. A. (2021). In-vitro diffusion study of ibuprofenn-?-cyclodextrin inclusion complex nanogel. Pharmaciana, 11(2), 213-224. https://doi.org/10.12928/pharmaciana.v11i2.20024

Kartini, K., Hardianti, D., \& Hadiyat, M. A. (2021). Identification of Phyllanthus niruri by FTIR spectroscopy with chemometrics. Pharmaciana, 11(2), 251-260. https://doi.org/10.12928/pharmaciana.v11i2.15954

Kulig, D., Zimoch-Korzycka, A., Król, Ż., Oziembłowski, M., \& Jarmoluk, A. (2017). Effect of filmforming alginate/chitosan polyelectrolyte complex on the storage quality of pork. Molecules, 22(1), 98-114. https://doi.org/10.3390/molecules22010098

Kumar, S. V., Tarun, P., \& Kumar, T. A. (2013). Transdermal drug delivery system for non-steroidal anti inflammatory drugs: A review. Indo American Journal of Pharmaceutical Research, 3, $3588-3605$

Motov, S., Butt, M., Masoudi, A., Palacios, W., Fassassi, C., Drapkin, J., Likourezos, A., Hossain, R., Brady, J., Rothberger, N., Flom, P., Zerzan, J., \& Marshall, J. (2020). Comparison of Oral Ibuprofen and Acetaminophen with Either Analgesic Alone for Pediatric Emergency Department Patients with Acute Pain. Journal of Emergency Medicine, 58(5), 725-732. https://doi.org/10.1016/j.jemermed.2020.02.010

Patel, H., Patel, U., Bhimani, B., Daslaniya, D., \& Patel, G. (2012). Transdermal drug delivery system 
as prominent dosage forms for the highly lipophilic drugs. International Journal of Pharmaceutical Research Bio-Science, 1(3), 42-65. https://doi.org/10.31638/IJPRS.V1.I1.00018

Pratiwi, G., Martien, R., \& Murwanti, R. (2019). Chitosan nanoparticle as a delivery system for polyphenols from meniran extract (Phyllanthus niruri 1.): Formulation, optimization, and immunomodulatory activity. International Journal of Applied Pharmaceutics, 11(2), 50-58. https://doi.org/10.22159/ijap.2019v11i2.29999

Pratiwi, G., Susanti, S., \& Shiyan, S. (2020). Application of factorial design for optimization of pvchpmc polymers in matrix film ibuprofen patch-transdermal drug delivery system. Indonesian Journal of Chemometrics and Pharmaceutical Analysis, 1(1), 11-22. https://doi.org/10.22146/ijcpa.486

Ramkanth, S., Jayaprakash, S., \& Vimalakannan, T. (2015). Formulation and evaluation of monolithic drug in adhesive type patch containing tenoxicam. International Journal of Pharma Sciences and Research, 6(04), 654-659

Romero-Chávez, M. M., Pineda-Urbina, K., Pérez, D. J., Obledo-Benicio, F., Flores-Parra, A., Gómez-Sandoval, Z., \& Ramos-Organillo, Á. (2018). Organotin(IV) compounds derived from ibuprofen and cinnamic acids, an alternative into design of anti-inflammatory by the cyclooxygenases (COX-1 and COX-2) pathway. Journal of Organometallic Chemistry, 862, 58-70. https://doi.org/https://doi.org/10.1016/j.jorganchem.2018.02.049

Sabati, A. M., Ali, M. A. M., \& Ali, B. A. (2017). Formulation and in-vitro evaluation of baclofen transdermal patchhes. Asian Journal of Pharmaceutices, 2017(86), 1-28

Santos, L. F., Correia, I. J., Silva, A. S., \& Mano, J. F. (2018). Biomaterials for drug delivery patches. European Journal of Pharmaceutical Sciences, 118, 49-66. https://doi.org/https://doi.org/10.1016/j.ejps.2018.03.020

Sarath, C., Shijith, K. V, Vipin, K. V, \& Augusthy, A. R. (2013). Formulation and evaluation of bisorolol fumarate buccal patchs by using selected polymers. International Jounal of Pharmaceutical, Chemical and Biological Sciences, 3(3), 854-860

Shiyan, S., Arifin, A., Amriani, A., Herlina, \& Pratiwi, G. (2020). Immunostimulatory activity of ethanol extract from calotropis gigantea 1. Flower in rats against salmonella typhimurium infection. Research Journal of Pharmacy and Technology, 13(11), 5244-5250. https://doi.org/10.5958/0974-360X.2020.00917.8

Shiyan, S., Hertiani, T., Martien, R., \& Nugroho, A. K. (2018). Optimization of a novel kineticassisted infundation for rich-egcg and polyphenols of white tea (Camellia sinensis) using central composite design. International Journal of Applied Pharmaceutics, 10(6), 259-267. https://doi.org/10.22159/ijap.2018v10i6.29654

Shiyan, S., Shiyan, S., Martien, R., \& Nugroho, A. K. (2019). Optimization and validation of rphplc/uv detection for several compounds simultaneously in semi-purified extract of white tea. Rasayan Journal of Chemistry, 12(3), 1098-1109. https://doi.org/10.31788/RJC.2019.1235276

Singh, A., \& Prajapati, U. K. S. S. K. (2017). A review on mucoadhesive buccal patches. International Journal of Research and Development in Pharmacy \& Life Sciences, 06(04), 2654-2660. https://doi.org/10.21276/ijrdpl.2278-0238.2017.6(4).2654-2660

Tyagi, S., \& Goyal, K. (2017). Transdermal drug delivery system: Quality approaches and evaluation. Innovat International Journal of Medical and Pharmaceutical Sciences, 2(3)

Wang, Y., Han, Q., Zhang, H., \& Yan, Y. (2020). Evaluation of the binding interactions of pacetylaminophenol, aspirin, ibuprofen and aminopyrine with norfloxacin from the view of antipyretic and anti-inflammatory. Journal of Molecular Liquids, 312, 113397. https://doi.org/https://doi.org/10.1016/j.molliq.2020.113397

Weissman, S. A., \& Anderson, N. G. (2015). Design of experiments (DoE) and process optimization. A review of recent publications. Organic Process Research and Development, 19(11), 16051633. https://doi.org/10.1021/op500169m 